\title{
The Dynamics between Unified Basque \& Dialects in the Northern Basque Country: A Survey Based on Perceptual Dialectology
}

\author{
Jean-Baptiste Coyos \\ Basque Text \& Language Study Center IKER - UMR 5478 (Bayonne - France) \\ \& Royal Academy of the Basque Language \\ Château Neuf - Place Paul Bert 64100 Bayonne France
}

\begin{abstract}
Today Unified Basque, a standardised written version of Basque created by the Academy of the Basque Language from the 1960s onwards and which is now widely codified, coexists alongside the Northern Basque Country's dialects (NBC, France). Understanding the relationship between these different forms of the Basque language is necessary in order to implement an appropriate language policy. In this paper we present the answers to the open-ended questions of a survey and accompanying comments. Based on Perceptual Dialectology, the questionnaire was completed by 40 people working in Basque in the NBC: writers, teachers, journalists, translators and language technicians. The main objective was to gather their opinions regarding Unified Basque and the dialects. The respondents were chosen according to the following criterion: they are all language prescribers, working in the language and providing a model of the Basque language for society. The main results of the survey are as follows: $95 \%$ of respondents think that Unified Basque is necessary in the NBC, $92.5 \%$ believe that the specificities of the NBC's linguistic varieties should be preserved, $80 \%$ that Unified Basque does not harm the NBC's dialects and more than half that there is now a form of Unified Basque specific to the NBC.
\end{abstract}

Keywords: Unified Basque, Basque dialects, Northern Basque Country, Perceptual Dialectology, survey (2018)

\section{Introduction: the Basque language today, Unified Basque and type of diglossia ${ }^{l}$}

The Basque language, or euskara in Basque, is Western Europe's only living pre-Indo-European language. Today it is spoken on both sides of the Franco-Spanish border. It is present in France in the western part of the PyrénéesAtlantiques department (in the provinces of Labourd, Lower Navarre and Soule), also known as the Northern Basque Country, and in the north-western part of Spain, in the Basque Autonomous Community (provinces of Álava [in the North], Biscay and Guipuzkoa), and in the Foral Community of Navarre (primarily in the north-western part). This Spanish part is also known as the Southern Basque Country. The population of the Northern Basque Country was 298,664 inhabitants on 1 January 2016, that of the Basque Autonomous Community was 2,189,000 inhabitants and that of Navarre 640,790 inhabitants in 2014.Across the entire Basque Country, it was estimated that $28.4 \%$ of the population aged 16 and over was bilingual (Basque/Spanish or Basque/French) in 2016 (Basque Government 2016). This percentage is constantly increasing. Conversely, in 2016 in the Northern Basque Country, the number of bilinguals was estimated at 51,200 and represented $20.5 \%$ of the population, a percentage rate in constant decline except among the younger generations (Office Public de la Langue Basque 2017). Basque is a minority language, both in France, compared to French, and in Spain, compared to Castilian Spanish.

Unified Basque (literal translation of the Basque euskara batua) is a standardised written version of Basque, created by the Royal Academy of the Basque Language from the 1960s onwards, and which is now widely codified. It is mainly based on the central Basque dialect spoken in Gipuzkoa and on written traditions. It has become the language used orally and in writing in government (especially in the Southern Basque Country), in education up to higher education, in the mass media, in literature, etc. It is used by new speakers that have not learned any local dialect, especially in cities, where it is no longer spoken (Bilbao, Vitoria, Pamplona and San Sebastian), and has become the mother tongue of some children. It is also worth noting that there are some difficulties for speakers of non-central dialects in terms of mutual comprehension.Ferguson's classical definition of diglossia (1959) in which two varieties of the same language are used by a single language community could be applied to the Basque language, both in the Northern Basque Country (NBC) and in the Basque Country as a whole.

\footnotetext{
${ }^{1}$ This paper is a revised and expanded version of a paper written in Basque (Euskera, 2018, 63-2, Bilbao: Academy of the Basque Language). It is intended for those who are not familiar with the current sociolinguistic situation of the Basque language.
} 
Indeed, the everyday language variety of a part of the NBC's inhabitants is the dialect learned at home, and the second, a kind of standard Basque specific to this territory, is used in certain formal situations such as academic education. Nevertheless, unlike this classical definition, standard Basque is also used for ordinary conversation and, as mentioned above, it has some young native speakers in the NBC too. This standard is used in ordinary conversation among speakers who have not learned a dialect and, for those who do speak one, due to difficulties in understanding each other, in particular the speakers of the easternmost dialect, Souletine dialect.

Understanding the relationship between unified Basque and the NBC's dialects, the dynamics and the ongoing evolution at stake is therefore necessary to implement an appropriate language policy. It should be noted that Basque has benefitted from public language policy since 2004.

\section{The Euskara Eskuz, Esku (EEE) project and the survey ${ }^{2}$}

Unified Basque has progressed a great deal over the last forty years, including in the Northern Basque Country. The need for it is no longer called into question and it is well established in many walks of life, both for in spoken and written form. However, many issues remain. The first is perhaps defining what Unified Basque is. Is it strictly speaking the Basque which appears in the Royal Academy of the Basque Language's norms? To a certain extent, the answer to this question is yes. Are the different varieties of Basque used in Bilbao and Bayonne changing due to the influence of Spanish and Biscayan, or French and the dialects of the NBC? This is also the case. Koldo Zuazo calls these "local" forms of Unified Basque (2005, 231. or.). Therefore, without going into greater detail at this point, we can say that nowadays unified Basque is complex, has many varieties and is still evolving. Like all regulated languages, it is not at all monolithic.

In the context of this complex linguistic situation, the Royal Academy of the Basque Language set up the Euskara Eskuz Esku (EEE) project in order to answer the needs, doubts and questions of the NBC's native-Basque speakers, as well as those learning the language. The aim of the Euskara Eskuz Esku project is to develop a new linguistic tool for Basque-speakers from the Northern Basque country, which takes into account language diversity. By constantly creating a usable and updated digital support, the objective is to directly answer the questions of Basque-speakers via a website or e-mail. This support will provide the recommendations and rules proposed by the Royal Academy of the Basque Language with simple articles in alphabetical order, divided into linguistic categories andhighlighting those which refer to the Northern Basque Country's linguistic diversity.

We can, for example, quote the 5th rule, "Ene/Nire, Niri". In a single page of text, firstly the Royal Academy of the Basque Language observes that ene is the oldest form, "from Biscayan to Souletin". Later, "in the late 17th century, nere appeared" and finally nire, first in Biscayan. Consequently, "In this case, taking into account how old and widespread it is, niri should be given priority". However, the rule in the final table is as follows: "The Royal Academy of the Basque Language's decision is as follows: the pronoun $n i$ with noren should use nire (and, of course, niretzat, nirekin), and similarly ene, at least in formal contexts. With the case nori,niri should be used". This is the work of EEE: in this case, for example, to show that ene as usedin the Northern Basque Country has not been excluded by the Royal Academy of the Basque Language and in this territory nire, which has begun to be usedshould not be given priority, since this would be supposedly be "true" unified Basque. Ene should therefore be taught in ikastolas (Basque-medium schools) and adult Basque language learning centres.

Generally, the aim is to show how Unified Basque can be achieved in the Northern Basque Country, bearing in mind it is the speakers themselves who make this decision. At the end of the chain, the speaker adapts the language, in our case Basque, making it evolve. A language academy or institution can put forward proposals, but in the end it is the users, ie. the speakers, who decide when using the language.

In this paper, we present the initial results provided as part of the EEE project. The main aim of this survey is to analyse how unified Basque and the dialects interact with each other in the Northern Basque Country, and what the future holds in the eyes of the respondents, or to put it another way, how the survey's participants see Basque's language ecosystem in this territory. We shall hereafter present the survey and the participants. However, first of all, we shall present our theoretical framework, that of perceptual dialectology.

\footnotetext{
${ }^{2}$ The Euskara Eskuz Esku (The Basque Language from Hand to Hand) project has been 65\% co-financed by the European Regional Development Fund (ERDF) through the Interreg V-A Spain France Andorra programme (POCTEFA 2014-2020). POCTEFA aims to reinforce the economic and social integration of the French-Spanish-Andorran border. Its support is focused on developing economic, social and environmental cross-border activities through joint strategies favouring sustainable territorial development.
} 


\section{About Perceptua IDialectology}

\section{What is perceptual dialectology?}

Perceptual dialectology falls under the heading of sociolinguistics and is part of what is referred to as folk linguistics, which looks at how non-linguists understand dialectal variation and its status. Rather than studying language phenomena, perceptual dialectology studies what we may refer to as the language awareness of speakers. The linguistic beliefs, feelings and attitudes of speakers influence their language behaviour (Cramer, p. 1). Marie-Anne Paveau states: “(...) popular proposals are not necessarily false or need to be discarded from science, they are perceptual, subjective and incomplete knowledge, to be used as part of scientific language data" (2008, p. 94). "Therefore, scientific linguistics should use folk linguistics as a collection of data, which is not collected in a scientific manner by a scientific linguist". This common feature in social science with regard to scientific observation is described by Paveau: "(...) scientific observation has to be removed from scientific fragility and subjective positions which are often idolectal" (ibid., p. 107).Furthermore, by understanding how a language community's speakers' perceive the language, perceptual dialectology can help implement more detailed language policies (Cramer, p. 2). This is one of the aims of the EEE project: to understand the extent to which Unified Basque is accepted in the NBC, the status of dialects and the value ascribed to them, in order to improve coordination between these different types of Basque.

\section{Perceptual dialectology \& its usefulness}

Perceptual dialectology can also provide other tools and information.

"An individual's linguistic awareness may appear in different ways and may be: i) explicit:through a speaker's linguistic beliefs, knowledge (intuitive), opinions or conclusions (in that case, we can refer to an explicit linguistic awareness); ii) implicit: characterised by a speaker's linguistic representation, behaviour or attitudes (in this case, we can refer to an implicit linguistic awareness)" (Gally, p. 2)."Answers based on perceptual dialectology can be used, as a point of departure,to measure a language's prestige, attractiveness, knowledge and level of understanding” (Sanders. p. 3). This will be of use for our study.

"One of the aims of perceptual dialectology is "(..) to determine and understand, as well as explain certain linguistic phenomena, variation and changes in a given sociolinguistic community" (Berruto, quoted by Gally, p. 3). In this case, the aim is to try to understand the basis of Unified Basque in the Northern Basque Country, to what extent, in what form and how it is evolving, alongside this territory's dialects and varieties.

Given the above, why use perceptual dialectology in our project? We also want to analyse the linguistic beliefs, feelings and behaviour of Basque-speakers in the NBC with regard to Unified Basque. We want to measure this complex and changing linguistic reality, not as we see it, but rather through the eyes of those most affected by the linguistic reality of the Northern Basque Country with a group of survey respondents. In the fifth section we shall explain how we chose the survey's participants.

\section{Survey structure \& nature of the questions}

The questionnaire is intended for those working with the Basque language, the main aim being to collect opinions about Unified Basque and dialects in the Northern Basque Country. Our initial intuition and working hypothesis were that in this territory, although the dialects have more or less survived, inland at least, particularly in the province of Soule, at the same time a unifying process has been gaining momentum in the provinces of Labourd and Lower Navarre, especially amongst the younger generations, primarily through education, since family transmission is overall quite low. Furthermore, older native Basque-speakers, who learnt local varieties at home without being familiar with Unified Basque, are dying out. This is the overall trend in the Northern Basque Country, where Basque-speakers increasingly know about and master Unified Basque, or at least a form of Unified Basque, even if it is not that of the Royal Academy of the Basque Language (cf. 1st section). The responses were collected during 2018.

\section{Questionnaire}

There are fourteen questions, some closed (YES/NO) and others open. However, even in closed questions respondents were able to add comments. Answers and comments are given in section 6 . The questions were as follows.

1. In your opinion, is there a form of Unified Basque specific to the Northern Basque Country?

2. If you answered yes to the above question, do you think there is a written form of Unified Basque in the Northern Basque Country?

3. However, if you answered yes to question 1, do you think there is a specific spoken form of Unified Basque in the Northern Basque Country? 
In the first group of 3 questions, we analyse whether there is a form of Unified Basque specific to the Northern Basque Country and what its features are. Obviously, not all respondents share the same definition of Unified Basque. Consequently, this is one of the obstacles for respondents, since they do not all understand questions in the same way.

4. What are the issues regarding Unified Basque in the Northern Basque Country?

5. Does Unified Basque harm the Northern Basque Country's dialects?

In this second group of questions the aim is to endeavour to analyse whether there are inevitably problems in the relationship between Unified Basque and the dialects. We did not want to take sides in the debate on whether Unified Basque could jeopardise the dialects, etc., although some respondents may think this to be the case.

6. Should the Northern Basque Country's dialects be protected?

7. Is language diversity useful in the case of Basque?

The third group of questions deals with the value of the wealth of dialects in the Northern Basque Country and generally, whether the diversity of Basque is useful.

8. Do you think Unified Basque is necessary in the Northern Basque Country?

The eighth question is clear. Not all the respondents understood the same thing by "Unified Basque", but this issue was cleared up in their comments.

9. In your opinion, what are the biggest mistakes made in the Northern Basque Country? Which are the most common?

This question tried to show a different aspect of respondents. As we can see, they are all prescribers in one way or another (teachers, writers, journalists, translators, Basque language technicians, etc.), the aim of the question being to make them see how they viewed the issue of quality. This can also be of help for the creators and users of the EEE digital support: problems, doubts and possible "mistakes" in Basque ...

10. Where, when and with whom do you use Unified Basque?

11. Where, when and with whom do you use your dialect?

The aim here was to assess how respondents use either Unified Basque and/or the dialect.

12. How do you see the future of Unified Basque and dialects in the Northern Basque Country?

Here, of course, nobody can predict the future. The aim was to collect people's opinions and feelings, both optimistic and pessimistic, of those in favour of Unified Basque and those in favour of the dialects, etc.

\section{Would you like to add any comments about Unified Basque and/or the dialects in the Northern Basque Country?}

This open question gave respondents the possibility to add comments and many took advantage of this opportunity. On the 14th question, see below at the beginning of section 6 .

\section{Data collection method}

The survey was carried out in two ways. On the one hand, respondents filled in a digital document and returned it by email. The length of responses was unlimited. On the other hand, a face-to-face interview was carried out with ten respondents, each asked fourteen questions. The interviews were recorded and transcribed. Furthermore, some of those recorded also filled in a written questionnaire.The freedom enjoyed by the respondents gave a wide and rich corpus. Sometimes, they did not respond to all the questions and some mentioned other things, but always contributing something with regard to Unified Basque and the dialects, explaining their personal experience, feelings, beliefs and attitudes.

\section{Profile of respondents - Selection criteria}

In the tradition of perceptual dialectology, those who are not linguists, common speakers, are questioned in order to find out, for example, what they think are the areas where their speech variety is or is not spoken, maps, to define the boundaries of language variation. The research subjects were then provided, for instance, by asking common speakers to listen to a sample of different language varieties to measure how different they were, how comfortable they felt with them or how correct they were, etc.

Our aim is not to study common native speakers who are not familiar with Unified Basque. Some of these have never even heard the expression "Unified Basque". They do not fall within the scope of our study because the aim of the research is not to collect prejudices, stereotypes and clichés about Unified Basque or the dialects of the Northern Basque Country, often spread by those who do not even speak the language, and, of course, without analysing or researching the subject, without validating their affirmation. This could be the subject of further research.Our goal is to analyse the situation of Unified Basque in the Northern Basque Country, how it coexists alongside the dialects, etc. based on a survey. 
What criteria did we use to choose the respondents or informants? They were all, in one way or another, Basque language prescribers in the NBC, meaning they all work with Basque: they teach Basque or in Basque, including several dialectologists, or write and publish their work in Basque, or are journalists, or translate from French into Basque mainly or vice-versa, or are Basque language technicians in local authorities, etc. This means they pass on the Basque language in public life, they provide Basque to be listened to or read and therefore are prescribers. They are Basque "model" providers, each with their own particular model.

Despite the fact that most of the time they are not linguists, they have to make choices. What type of Basque to use: their own dialect, if they have one, or Unified Basque? Which type of Unified Basque? Who is the audience? What is the context? What is the aim, etc?In that sense, Marie-Anne Paveau's comment seems relevant here: "Are there any discrepancies between a speaker who is not a linguist and one who is? The philosopher, Michael Devitt, says this is not the case and believes that the intuitions of linguists are better than those of folk linguists since intuitions are not as innate as we may believe, but full of theories" (ibid., p. 104). In order to determine this observation, we can say that the intuitions of non-linguists are also based on theories, or rather micro-theories, although these are not thought out or cultivated. They are based on language ideologies, spread by schools, the media and leading opinion, both in France and Spain.

\section{Respondent profile: personal data}

Before answering the fourteen questions (cf. section 4), the respondents provided some personal data: first name(s), surname, date, date of birth, place of birth, place of residence, how they learnt Basque and e-mail address. Those who answered the written survey all provided this information. However, we were unable to collect all the personal data of those who only answered the recorded interview. This is why in the tables below there is an "unknown" column.

The survey stipulated that the results would be anonymous and the 14th question of the EEE project asked respondents if they would be prepared for their name to appear in the list of participants (cf. section 3 of full survey). All, with the exception of two, accepted their names appearing on the list.

Age - Sex

\begin{tabular}{|l|l|l|l|l|l|l|l|}
\hline Age group & & $20-34$ & $35-50$ & $50-64$ & $\geq 65$ & unknown & $\%$ \\
\hline Female & $\mathbf{1 4}$ & & $\mathbf{4}$ & $\mathbf{7}$ & $\mathbf{3}$ & & $35.00 \%$ \\
\hline Male & $\mathbf{2 6}$ & & $\mathbf{7}$ & $\mathbf{8}$ & $\mathbf{1 0}$ & $\mathbf{1}$ & $65.00 \%$ \\
\hline$\%$ & & & $27.50 \%$ & $37.50 \%$ & $32.50 \%$ & $2.50 \%$ & \\
\hline
\end{tabular}

With regard to the sex parameter, the two groups were not equally balanced. The female group only represented one third of respondents. This could be improved.

The age groups are more equally balanced, but the 20-34 age group is empty. This is not because in this age group there are less "prescribers", although there are few young writers in the NBC. There are Basque teachers especially and Basque language technicians. However, the researchers know less respondents in this category. In any case, this agegroup is to be studied more precisely, to understand, amongst other things, how they consider Unified Basque, because everyone has learned it at school, in one way or another, which is not the case for older generations.

\section{Place of birth}

\begin{tabular}{|l|l|l|l|l|l|}
\hline Province & Labourd & Lower Navarre & Soule & SBC & France \\
\hline & $\mathbf{1 1}$ & $\mathbf{1 5}$ & $\mathbf{6}$ & $\mathbf{5}$ & $\mathbf{3}$ \\
\hline$\%$ & $27.50 \%$ & $37.50 \%$ & $15.00 \%$ & $12.50 \%$ & $7.50 \%$ \\
\hline
\end{tabular}

Almost $40 \%$ of respondents were born in Lower Navarre, three outside the Basque Country (two in Paris and one in $\mathrm{Pau}$ ) and five in the Southern Basque Country (SBC).

This data is interesting to find out which dialect they heard or learnt during childhood, especially when they say they learnt Basque at home (cf. below). 


\section{Place of residence}

\begin{tabular}{|l|l|l|l|l|l|}
\hline Province & Labourd & Lower Navarre & Soule & SBC & Unknown \\
\hline & $\mathbf{2 4}$ & $\mathbf{6}$ & $\mathbf{7}$ & $\mathbf{2}$ & $\mathbf{1}$ \\
\hline$\%$ & $60.00 \%$ & $15.00 \%$ & $17.50 \%$ & $5.00 \%$ & $2.50 \%$ \\
\hline
\end{tabular}

The appeal of the coast of Labourd can clearly be seen if we compare this with place of birth. Bayonne-Anglet-Biarritz (including Saint-Pierre-d'Irube and Villefranque) is the NBC's main conurbation. In the case of Soule, place of birth and place of residence are comparable. However, Lower Navarre has lost almost two out of every three respondents.

How did you learn Basque?

\begin{tabular}{|l|l|l|l|l|l|}
\hline & Home & Ikastola & AEK & Self-taught & Unknown \\
\hline Home & $\mathbf{2 6}$ & & & & \\
\hline Ikastola & $\mathbf{2}$ & $\mathbf{1}$ & & & \\
\hline AEK & & & $\mathbf{1}$ & $\mathbf{1}$ & \\
\hline Self-taught & $\mathbf{7}$ & & & $\mathbf{1}$ & \\
\hline Unknown & & & & & $\mathbf{1}$ \\
\hline \% & $87.50 \%$ & $2.50 \%$ & $2.50 \%$ & $5.00 \%$ & $2.50 \%$ \\
\hline
\end{tabular}

One or two answers should be taken into consideration. This research subject is worthy of long comments, but since the question was quite short and the answer was either one word or sentence. Moreover, some informants gave two points of view, at home and school, for example, if they needed to distinguish spoken and written Basque, or AEK (association of night-schools) and self-teaching, etc. In these cases, two viewpoints are shown in the table, crossing the lines and columns.

On the other hand, amongst those who had only learnt Basque at home, some improved, lost or recovered their knowledge of the language at school or through self-teaching. Family transmission is predominant with almost $90 \%$. Of these $20 \%$ added self-teaching, ie. lifelong learning, or they forgot Basque before recovering it, or having learnt to speak it during childhood, they learnt how to write it at a later date. These are however assumptions.

\section{Profession / Former profession - Main job}

\begin{tabular}{|l|l|l|l|l|}
\hline & & $\mathbf{\%}$ & $\begin{array}{l}\text { Full member of the } \\
\text { Academy }\end{array}$ & Honorary - Assistant member \\
\hline Researcher - Dialectologist & $\mathbf{2}$ & $5.00 \%$ & & $\mathbf{2}$ \\
\hline Teacher & $\mathbf{1 1}$ & $27.50 \%$ & $\mathbf{1}$ & $\mathbf{2}$ \\
\hline Writer & $\mathbf{6}$ & $15.00 \%$ & $\mathbf{2}$ & $\mathbf{1}$ \\
\hline Journalist & $\mathbf{6}$ & $15.00 \%$ & & $\mathbf{3}$ \\
\hline Basque technician & $\mathbf{6}$ & $15.00 \%$ & & \\
\hline Translator & $\mathbf{4}$ & $10.00 \%$ & & \\
\hline Other & $\mathbf{5}$ & $12.50 \%$ & & \\
\hline
\end{tabular}

In the survey this question was not asked, but since we knew the profession of all the respondents, we were able to fill it in ourselves. 
We distinguished seven categories. In the first line we put Researcher Dialectologist since they research Unified Basque and dialects as part of their job. We can assume that, theoretically, they were better acquainted with the research subject than the other respondents. However, members of other categories could also have very precise knowledge. These are secondary school teachers, university lecturers and adult language trainers; we did not distinguish these. Two researchers are also lecturers.

The teachers category was the largest with a third of respondents.Those in the "Other" category work in the field of Basque culture and use Basque on a daily basis, both spoken and written.Full members of the Royal Academy of the Basque Language, as well as assistant and honorary members, represented more than $25 \%$ of respondents.

\section{Closed questions: answers}

We shall now analyse the answers to the eight closed questions:1, 2, 3, 5, 6, 7 and 8. Our research subject's final question, no. 14, did not provide any information.The table had four categories: "YES", "NO", "YES and NO" when the answer was not clear, and "No Answer". Whether they were asked in the survey to do so or not, most respondents provided certain comments to qualify their answer. We shall mention some of these below.

Question $n^{\circ}$ 1: In your opinion, is there now a form of Unified Basque specific to the Northern Basque Country?

\begin{tabular}{|l|l|l|}
\hline YES & $\mathbf{2 3}$ & $57.50 \%$ \\
\hline NO & $\mathbf{1 1}$ & $27.50 \%$ \\
\hline YES and NO & $\mathbf{3}$ & $7.50 \%$ \\
\hline No answer & $\mathbf{3}$ & $7.50 \%$ \\
\hline
\end{tabular}

Over half of respondents believe that there is now a form of Unified Basque specific to the Northern Basque Country, less than one third thinks this is not the case, and three respondents answered both yes and no.In some cases, the comments provide extra clarity and deserve a longer explanation, which we shall do in another paper. However, some are worth mentioning here without going into detail.Those who answered yes and added comments give as an example the weekly publication Herriaor the supplementIpar Euskal HerrikoHitza to the newspaper Berria. These state that thanks to Basque-medium schools (ikastolas) there is a standard (being created), especially if we compare this to the Southern Basque Country. However the situation is rather unclear, since it has been "contaminated" by both French and the NBC's dialects. We can therefore say that this special form of Basque is not so "unified".

Here is a comment of a respondent: "In my view, there is a standard emerging between the Basque of Labourd and Lower Navarre. I'd call it a standard". For a minority of respondents there has been a minimal "Unified Basque" for a long time in the NBC based on the Basque of Labourd and Lower Navarre in magazines, such as Eskualduna, Gure Herria and Herria, or various church documents (Sunday school, books for mass, etc).

Amongst those who answered no and added comments, the main comment was that between Larrau (Soule) and Hendaye (South Labourd), it cannot be said there is a single form of Unified Basque. For example: "Those who know it, use it. I don't know it. I think we mix everything up, “our” Basque and Unified Basque. I wouldn't say that we have a special form of Unified Basque". For a small minority there is a single Unified Basque, for the entire Basque Country.

Here is the comment of one respondent who answered "Yes and No": "It's difficult to say either yes or no. I'd say there's a trend, but I'm not sure if the same "Northern Unified Basque" is spoken in Saint-Palais and Hendaye, I don't think so."

Question $n^{\circ}$ 2: If you answered yes to the above question, do you think there is a written form of Unified Basque in the Northern Basque Country?

\begin{tabular}{|l|l|l|}
\hline YES & $\mathbf{2 0}$ & $50.00 \%$ \\
\hline NO & $\mathbf{3}$ & $7.50 \%$ \\
\hline YES and NO & $\mathbf{5}$ & $12.50 \%$ \\
\hline No answer & $\mathbf{1 2}$ & $30.00 \%$ \\
\hline
\end{tabular}


If we compare it to the first table, in the NBC half of respondents said there is a written Unified Basque. However, a much smaller number of respondents said this was not the case. Logically, if they answered no to the first question, they also answered no to the second.

We added an open question to the 2nd closed "If YES, what are its features?" question. In short, amongst those who answered yes to this question, they believe they apply the rules of Unified Basque (Royal Academy of the Basque Language), using new words and the standard verb, but however keeping the vocabulary and sayings of the NBC: therefore, something close to Unified Basque. This is why we make the distinction between writers from the Northern and Southern Basque Country. Comment: "It has absorbed many words from the dialects [NBC Unified Basque], numerous new words and a standard verb. This comes, in my opinion, from teaching in Basque, radio, etc.".Very few said no and answered this question. They think in the NBC things are being mixed up.

The comment of someone who said both "Yes and No": "It's not a mistake ... Although I think the NBC's "Unified" Basque is not completely correct, there are some traces of the Northern Basque Country in some written documents".

Question $n^{\circ}$ 3. However, if you answered yes to question 1, do you think there is a specific spoken form of Unified Basque in the Northern Basque Country?

\begin{tabular}{|l|l|l|}
\hline YES & $\mathbf{2 0}$ & $50.00 \%$ \\
\hline NO & $\mathbf{6}$ & $15.00 \%$ \\
\hline YES and NO & $\mathbf{2}$ & $5.00 \%$ \\
\hline No answer & $\mathbf{1 2}$ & $30.00 \%$ \\
\hline
\end{tabular}

As with question no. 2, if we compare it with the 3rd table above, half of respondents think there is a specific unified form of spoken Basque in the NBC. However, those who answered no are in a minority. Logically, those who answered no to question no. 1 also answered no to question no. 3 .

An open question was added to closed question no. 3: "If you answered YES, what are its distinguishing features?". Those who answered yes and also answered the open question said this specific form of Basque is more marked in writing than in speaking. The local phonetics and prosody are maintained, except those of Soule. In that respect, speakers know how far they can go when speaking with someone, depending on where they are from in the NBC and what dialect they speak. On the other hand, the "unified Basque" of new Basque speakers and that of those who speak a dialect should be distinguished.

Here is the comment of one respondent who did not think there is a Unified Basque specific to the Northern Basque Country: "In spoken Basque the situation is less clear. Rather than a specific Unified Basque for the Northern Basque Country, I'd say all Basque speakers from the Northern Basque Country can easily understand each other. There are several reasons for this: Basque-speakers meet in the capital of the Northern Basque Country, Bayonne, the strength of Basque radio, the development of Basque-medium schools".

As we have already seen, many did not answer the first question on whether there was a specific form of Unified Basque in the Northern Basque Country, and one third said there was not.

Question no. 5: Does Unified Basque harm the Northern Basque Country's dialects?

\begin{tabular}{|l|l|l|}
\hline YES & $\mathbf{3}$ & $7.50 \%$ \\
\hline NO & $\mathbf{3 2}$ & $80.00 \%$ \\
\hline YES and NO & $\mathbf{3}$ & $7.50 \%$ \\
\hline No answer & $\mathbf{2}$ & $5.00 \%$ \\
\hline
\end{tabular}

$80 \%$ of respondents believe the existence of Unified Basque does not harm the dialects of the Northern Basque Country. 7,5\% said the opposite. Some answered and added comments, which can be summarised as follows. Those who said no believe Unified Basque itself does not harm the dialects, although it does if it is not used correctly, or if we think that the dialects are insufficient or wrong, or that the variety specific to the Southern Basque Country is true Unified Basque. 
However, French does harm them. That Unified Basque goes against the dialects is a "false argument", provided they are all used in appropriate situations. A comment by way of an example: "French is much more harmful to the dialects than Unified Basque".

The three who answered yes said that the Northern Basque Country's Basque-medium schools and night-schools, with the exception of the province of Soule, harm the knowledge and use of local varieties of Basque by teaching and using a type of Unified Basque, and that the dialects will be increasingly marginalised. One said: "That means, in the long term, if Unified Basque spreads through education, the dialects will be marginalised, less and less people will speak them and over time they may disappear". Another said: "Yes, logically. The way people speak, the vocabulary and words we use will gradually disappear".

Question $n^{\circ}$ 6. Should the Northern Basque Country's dialects be protected?

\begin{tabular}{|l|l|l|}
\hline YES & $\mathbf{3 7}$ & $92.5 \%$ \\
\hline NO & $\mathbf{0}$ & $0 \%$ \\
\hline YES and NO & $\mathbf{2}$ & $5.00 \%$ \\
\hline No answer & $\mathbf{1}$ & $2.50 \%$ \\
\hline
\end{tabular}

With this question, there is more unanimity: $92.5 \%$. They believe the Northern Basque Country's dialects should be protected. "Why?" With this question, comments and explanations were asked for, and almost all respondents answered.

Here are two comments about this specificity: "Yes, without a doubt, as far possible, but without any nostalgia: this makes people fearful and the language become less natural, which should not be the case". "I think we need perspective and we need to reflect about the overall situation of Basque. (...) What do we want for the future? To keep Basque alive, as one of the world's languages, pass it on and spread it. That's why we need to strengthen its roots and body, by consolidating Unified Basque. Otherwise it will disappear, it will be swallowed up by other languages".

Other respondents made a more general comment, saying that without marginalising the Northern Basque Country's specificities, we are now in the process of unifying Basque: "Standardisation is what drives language. Our unified language is still too young, in my opinion, it's still work in progress. Once we're all able to use it, then it'll be unified".

The most commonly used expression is "rich" or "wealth": 21 out of 36 respondents used one of these words (wealth, enriching, rich, richer, etc, also treasure). The Northern Basque Country's dialects feed Unified Basque, they are markers of identity, they make language pleasurable, they enable inter-generational communication. However, they are not protected enough and are becoming impoverished.

This respondent links dialect to identity: "The Basque I've spoken since I was small has been that of Saint-Jean-Piedde-Port, it's a special dialect. The dialects have an identity, we know the person speaking is from there and I personally think that's an advantage".

Here is a comment by a mother about using a dialect and the transformation in the Northern Basque Country: "It depends on everyone's own feelings. I use the Basque of Ciboure when I speak with my children, they learn the Basque of Mendionde at the ikastola, it's a wonderful mixture. I don't see specificities as restrictive (in Hendaye they speak one way, in Saint-Jean-Pied-de-Port another ...), but rather as a richness".

This respondent also mentioned discrimination against Basque-speakers and self-depreciation: "Even more than the dialects of Basque, all Basque speakers need protecting and therefore "Basque-speakers who speak a dialect" too. Basque speakers were discriminated against because they did not fully master French or spoke with an accent and this continues to be the case today (even though not quite so acutely). Added to this, the fact that certain Basque-speakers show contempt for their "own" form of Basque, eg. because it is the Basque they learnt at home, not at school. This way of thinking has had a negative effect on both usage and transmission".

No respondents stated that the specific varieties of Basque in the NBC should not be protected. Therefore, in this case, opinions are very clear. 
Question $n^{\circ}$ 7: Is language diversity useful in the case of Basque?

\begin{tabular}{|l|l|l|}
\hline YES & $\mathbf{3 5}$ & $87.50 \%$ \\
\hline NO & $\mathbf{1}$ & $2.50 \%$ \\
\hline YES and NO & $\mathbf{0}$ & $0 \%$ \\
\hline No answer & $\mathbf{4}$ & $10.00 \%$ \\
\hline
\end{tabular}

There is a large degree of unanimity with this general question. Yes, language diversity is positive for the Basque language.It is worth noting that question $\mathrm{n}^{\circ} 7$ is very close to question $\mathrm{n}^{\circ} 6$. Even when not asked, some respondents added comments.

It is important to have a variety of tools (Unified Basque, dialect, local variety, family language etc.), different registers. Here also, several respondents mention the notion of wealth. Language diversity makes the Basque language richer. Two comments. The first: "Having several possibilities is always a good thing, in all walks of life" and the second: "This language diversity brings wealth. That's something which is universal". Theonly respondent to have replied no did not leave any comments.

Question $n^{\circ}$ 8: Do you think Unified Basque is necessary in the Northern Basque Country?

\begin{tabular}{|l|l|l|}
\hline YES & $\mathbf{3 8}$ & $95.00 \%$ \\
\hline NO & $\mathbf{0}$ & $0 \%$ \\
\hline YES and NO & $\mathbf{1}$ & $2.50 \%$ \\
\hline No answer & $\mathbf{1}$ & $2.50 \%$ \\
\hline
\end{tabular}

This is the question which gave rise to the greatest unanimity. None of the respondents said no and just one said both yes and no. Overall, therefore, the respondents believe that there is a need for unified Basque in the Northern Basque Country. Almost all the respondents answered the question "Why?", mentioning the need for language unity to bring together the Basque-speaking community: "It's essential, both in the Northern and Southern Basque Country. Worldwide experience shows that in order to save a threatened language, unity is essential, not only a unified language, but also a unified community of speakers".

The respondents said that Unified Basque is needed for Basque-speakers to understand each other, with those who speak a dialect, those from across the border and the diaspora, eg. to understand the contemporary writer Bernardo Atxaga's works or Euskal Telebista (Basque Governement Television), the mass media, science and philosophy, in education and government... Since it is a threatened language, linguistic unity is needed to save the language as well as the for the unity of the linguistic community. Most new Basques only speak Unified Basque. The most commonly expressed reason was to ensure Basque-speakers are able to understand each other.

Four comments. First: "Why? To ensure mutual understanding. But we'd like to see them [Southern Basques] doing the same for us, but the other way round. Unified Labourdin has existed for over a century, without losing the dialects or sub-dialects". Second: "Because we are a people, the people who speak Basque and a language is not to divide people, but to enable them to communicate with each other. We can be both different and one". Third: "In the Northern Basque Country, Basque is not at all hegemonous. We shouldn't waste our energy".And finally: "In all languages the same thing has happened [having a unified language], so why not with Basque too?".

No respondent said in the NBC having a unified Basque is not necessary. Perhaps that is this survey's most important contribution.

\section{Conclusions}

In this paper, we have only explained the comments which respondents added to the closed questions. We shall provide explanations of open questions in another paper.We can say that this sample is representative with 40 respondents. However, few women or young people took part. 
As said in section 1, in 2016 in the Northern Basque Country there were an estimated 51,200 Basque-speakers, ie. $20.5 \%$ of the population (Basque Government, VI. Sociolinguistic Survey). It is estimated that there are less than 1000 who work with Basque, our target audience: teachers, writers, journalists, translators, Basque-language technicians, etc., of which teachers are the largest group. In the first section of this paper, we said that it was not easy to sum up the complex linguistic situation of the Northern Basque Country. However, overall, several trends can be observed in the survey.92.5\% of respondents believe the Northern Basque Country's linguistic specificities should be protected. The most commonly used description was "wealth".

$80 \%$ of respondents say unified Basque does not harm the dialects of the Northern Basque Country, but French does. Language diversity is useful for Basque: Unified Basque, the dialects and local varieties, providing various different registers. Is Unified Basque needed in the Northern Basque Country? This question received greatest unanimity with 95\%. It is needed for mutual understanding, between Basques, with Basques from the Southern Basque Country and the diaspora. It is needed in many walks of modern life, as is the case in other languages.

Over half of respondents believe that a specific form of Unified Basque exists in theNorthern Basque Country. Of these, some say that a Unified Basque has been in existence for a long time in the Northern Basque Country, based on Labourdin and Lower Navarrese. Today, overall, when this Unified Basque is written, they believe the rules set by the Royal Academy of the Basque Language are applied, using new words and the regulated verb, but with the lexis and sayings of Northern Basque. In the Northern Basque Country this influence can be seen more in the phonetics and prosody, along with the influence of French. This is also the case with the lexis. This Basque is more unified in its written form than in its spoken form, because its local phonetics and prosody are kept when spoken. Following this survey the next stage will be to analyse the results of open questions and these will be published, always with the aim of better understanding the relationship between Unified Basque and the dialects of the Northern Basque Country, of better understanding the degree of acceptance of Unified Basque and its integration into today's Basque language.

\section{References}

Academy of the Basque Language (1994). Ene/Nire, Niri, 5. araua (rule 5), Arau guztiak (All rules), www.euskaltzaindia.eus/hizkuntza-baliabideak/baliabide-orokorrak/arauak. (January 25, 2019)

Academy of the Basque Language. Arau guztiak - Euskaltzaindiaren arauak (All rules - Rules of the Academy of the Basque Language),www.euskaltzaindia.eus/hizkuntza-baliabideak/baliabide-orokorrak/arauak. (January 25, 2019)

Basque Autonomous Government (2016). VI.Inkestasoziolinguistikoa2016 (VI.SociolinguisticSurvey 2016), from www.irekia.euskadi.eus/.../VI_INK_SOZLG-EH_eus.pdf. (January 25, 2019)

Cramer, Jennifer (2016). Perceptual Dialectology, www.oxfordhandbooks.com/view/10.1093/oxfordhb/9780199935345.001.0001/oxfordhb-9780199935345-e60. (January 25, 2019)

Ferguson, Charles A. (1959). Diglossia, Word, 15, New York: 325-340.

Gally, Sylvia (2015). Variation linguistique perçue : quelques localités du Piémont occidental (Italie). Questions de méthodologie en dialectologie perceptuelle, Corela HS-16, in 2016 revues.org, https://journals.openedition.org/corela/4013. (January 25, 2019)

Office public de la langue basque (2017). VIème enquête sociolinguistique Pays basque nord, www.mintzaira.fr/fr/lalangue-basque/situation-socio-linguistique.html. (January 25, 2019)

Paveau, Marie-Anne (2008). Les non-linguistes font-ils de la linguistique ? Une approche anti-éliminativiste des théories folk, Pratiques - Linguistique, littérature, didactique, 139-140, https://journals.openedition.org/pratiques/1200. (January 25, 2019)

Sanders, Allison (2013). Développer une méthode de recueil de données sur la perception sociolinguistique : comment les jeunes perçoivent-ils l'occitan dans le Sud-Ouest de la France? Mémoire Master 1, UGA UFR LLASIC SLFLE - Université Grenoble Alpes. https://dumas.ccsd.cnrs.fr/dumas-00841377. (January 25, 2019)

Zuazo, Koldo (2005). Euskara batua Ezina ekinez egina(Unified Basque The impossible achieved by action), San Sebastian : Elkarlanean. 